\title{
Cyclopentenyl cytosine increases gemcitabine radiosensitisation in human pancreatic cancer cells
}

\author{
C van Bree ${ }^{*, 1}$, HM Rodermond', R Leen ${ }^{2}$, JP Medema' and ABP van Kuilenburg ${ }^{2}$ \\ 'Department of Radiation Oncology, Academic Medical Centre-University of Amsterdam, Laboratory for Experimental Oncology and Radiobiology, Centre \\ for Experimental Molecular Medicine, Amsterdam, The Netherlands; ${ }^{2}$ Department of Genetic and Metabolic Diseases, Academic Medical Centre- \\ University of Amsterdam, Amsterdam, The Netherlands
}

The deoxycytidine analogue $2^{\prime}, 2^{\prime}$-difluoro-2'-deoxycytidine (dFdC, gemcitabine) is a potent radiosensitiser, but has limited efficacy in combination with radiotherapy in patients with pancreatic cancer due to acute toxicity. We investigated whether cyclopentenyl cytosine (CPEC), targetting the 'de novo' biosynthesis of cytidine triphosphate (CTP), could increase dFdC cytotoxicity alone or in combination with irradiation in a panel of human pancreatic cancer cells (Panc-I, Miapaca-2, BxPC-3). To investigate the role of deoxycytidine kinase (dCK), the rate-limiting enzyme in the activation of dFdC, human lung cancer cells without (dFdC-resistant SWg) and with an intact $d C K$ gene (dFdC-sensitive SWP) were included. We found that CPEC $\left(100-1000\right.$ nmol $\left.I^{-1}\right)$ specifically reduced CTP levels in a dose-dependent manner that lasted up to $72 \mathrm{~h}$ in all cell lines. Preincubation with CPEC resulted in a dose-dependent increase in $\mathrm{dFdC}$ incorporated into the DNA only in $\mathrm{dFdC}$-sensitive cells. Consequently, CPEC increased the effectiveness of dFdC $\left(300 \mathrm{nmol} \mathrm{I}^{-1}\right.$ for $4 \mathrm{~h}$ ) only in $\mathrm{dFdC}$-sensitive cells, which was accompanied by an increase in apoptosis. We also found that CPEC enhanced the radiosensitivity of cells treated with $\mathrm{dFdC}\left(30-300 \mathrm{nmoll}^{-1}\right.$ for $\left.4 \mathrm{~h}\right)$. These results indicate that CPEC enhances the cytotoxicity of $\mathrm{dFdC}$ alone and in combination with irradiation in several human tumour cell lines with an intact $d C K$ gene. British Journal of Cancer (2008) 98, I226- 1233. doi:I0.1038/sj.bjc.6604287 www.bjcancer.com

Published online 18 March 2008

(c) 2008 Cancer Research UK

Keywords: cyclopentenyl cytosine; gemcitabine; ionising radiation; pancreatic cancer; radiosensitisation

Pancreatic cancer is the fourth leading cause of cancer death worldwide with an overall 5-year survival rate less than $5 \%$. At diagnosis, about half of all patients have unresectable, locally advanced disease, whereas $30 \%$ of the patients present with distant metastases, leaving only $20 \%$ candidates for surgery. Gemcitabine $\left(\right.$ Gemzar ${ }^{\circledR}, 2^{\prime} 2^{\prime}$-difluoro-2'-deoxycytidine, dFdC), a deoxycytidine analogue with a broad spectrum of antitumour activity against solid tumours, is considered to be the reference treatment for patients with locally advanced pancreatic cancer by many, but with only marginal clinical benefit (Burris et al, 1997). $2^{\prime}, 2^{\prime}$-Difluoro-2' deoxycytidine has been identified as a potent enhancer of radiosensitivity of human cancer cells, including pancreatic cancer cells, which is persistent up to $72 \mathrm{~h}$ after the end of drug exposure (Rockwell and Grindey, 1992; Shewach et al, 1994; Lawrence et al, 1996, 1997; Buchsbaum et al, 2002). Several phase I and II studies have investigated concurrent $\mathrm{dFdC}$ and radiotherapy, but acute gastrointestinal toxicity was encountered with standard doses of $\mathrm{dFdC}$ and radiotherapy, which depended on the irradiated volume (Crane et al, 2001; Wilkowski et al, 2006; Murphy et al, 2007). Either with a reduction of the $\mathrm{dFdC}$ dose or the radiation dose or the volume, concurrent chemoradiotherapy appears feasible. However, this will likely reduce the efficacy of treatment whereas

*Correspondence: Dr C van Bree; E-mail: c.vanbree@amc.uva.nl Received 4 October 2007; revised 3 I January 2008; accepted I February 2008; published online 18 March 2008 an increase in efficacy of the combined treatment for local tumour control is clearly required (Wilkowski et al, 2006; Yip et al, 2006; Murphy et al, 2007; Yamazaki et al, 2007).

Several approaches, based on increasing the anabolism of $\mathrm{dFdC}$ have been described to enhance its effectiveness (Duxbury et al, 2004; Giovannetti et al, 2004; Verschuur et al, 2004; Bierau et al, 2006). $2^{\prime}, 2^{\prime}$-Difluoro-2'-deoxycytidine is activated by intracellular phosphorylation to its active metabolites $\mathrm{dFdC}$ diphosphate and $\mathrm{dFdC}$ triphosphate. The initial phosphorylation to $\mathrm{dFdC}$-monophosphate is performed by deoxycytidine kinase $(d C K)$ and is the rate-limiting step. The activity of $d C K$ is feedbackinhibited by dCTP present in cells. The 'de novo' pathway for the synthesis of both cytidineribonucleotides and cytidinedeoxyribonucleotides is mediated by the enzymes CTP synthetase (CTPs). This pathway has been reported to be upregulated in solid tumours (Kizaki et al, 1980) and is therefore an attractive target for increasing the therapeutic ratio of $\mathrm{dFdC}$ and radiotherapy.

Cyclopentenyl cytosine (CPEC, NSC 375575) is a cytidine analogue which, in its active $5^{\prime}$-triphosphate form, is a noncompetitive inhibitor of CTPs leading to depletion of both cytidine pools and deoxycytidine pools (Kang et al, 1989; Verschuur et al, 2004; Bierau et al, 2006). Consequently, mRNA and protein levels as well as the activity of $d C K$ are elevated (Bierau et al, 2006), which enhance the effectiveness of $\mathrm{dFdC}$ in human leukaemia (Verschuur et al, 2004) and human neuroblastoma cells (Bierau et al, 2006). However, to date there is no information available whether CPEC could enhance $\mathrm{dFdC}$ effectiveness in human 
pancreatic tumour cell lines nor on the interaction between $\mathrm{dFdC}$ and radiation. In this report, we show that CPEC strongly enhances the effectiveness of $\mathrm{dFdC}$ alone and in combination with radiation in three human pancreatic tumour cell lines. We incorporated a dFdC-sensitive and a dFdC-resistant human nonsmall cell lung carcinoma (NSCLC) cell line (SWp and SWg respectively, van Bree et al, 2002) to show that these CPEC-induced effects can also be obtained in other human solid tumour cell lines and requires the presence of $d C K$ activity.

\section{MATERIALS AND METHODS}

\section{Drugs and chemicals}

Leibovitz-15 medium (L-15), DMEM, RPMI with HEPES and PSG $\left(100 \times\right.$ stock of $10000 \mathrm{U} \mathrm{ml}^{-1}$ penicillin, $10 \mathrm{mg} \mathrm{ml}^{-1}$ streptomycin and $20 \mathrm{mmoll}^{-1}$ glutamine) were purchased from GIBCO-BRL (Paisley, Scotland), cell proliferation kit II from Roche (Mannheim, Germany), dFdC from Eli Lilly (Nieuwegein, The Netherlands) and $\left[{ }^{3} \mathrm{H}\right]$-dFdC $\left({ }^{14} \mathrm{Ci} \mathrm{mmol}^{-1}\right)$ from Moravek Biochemicals (BREA, CA, USA). Cyclopentenyl cytosine (NSC 375575) was obtained from the Developmental Therapeutics Program, National Cancer Institute (Bethesda, MD, USA). All nucleotide standards were obtained from Sigma Chemicals (Zwijndrecht, The Netherlands). All other chemicals were of analytical grade and commercially available.

\section{Cell cultures}

Human pancreatic cell lines Panc-1, Miapaca-2 and BxPC-3 (American Type Culture collection, Manassas, VA, USA) were grown as monolayers in DMEM (Panc-1 and Miapaca-2) or RPMI (BxPC-3) supplemented with $10 \%$ heat-inactivated fetal bovine serum (FBS) and with PSG at $37^{\circ} \mathrm{C}$ at $5 \% \mathrm{CO}_{2}$. The human NSCLC SWp and its dFdC-resistant variant SWg have been described (van Bree et al, 2002; Jordheim et al, 2004). These cells were grown as monolayers in L-15 medium supplemented with $10 \%$ heatinactivated $\mathrm{FBS}$ and PSG at $37^{\circ} \mathrm{C}$ without additional $\mathrm{CO}_{2}$. All cell lines were passaged twice weekly to ensure exponential growth.

\section{Drug treatment and irradiation}

Cells were seeded ( 8500 cells per $\mathrm{cm}^{2}$ ) in Petri dishes and were allowed to attach overnight. Various doses of CPEC and dFdC were added from freshly prepared $100 \times$ stock solutions in sterile phosphate-buffered saline without refreshing the medium. Cells were irradiated with $\gamma$ rays from a ${ }^{137} \mathrm{Cs}$ source at a dose rate of approximately $0.7 \mathrm{~Gy}^{\mathrm{min}}{ }^{-1}$.

\section{Extraction and analysis of nucleotides and detection of radiolabelled $\mathrm{dFdC}$ metabolites}

For the analysis of the effects of CPEC alone on nucleotide triphosphate levels and for the detection of radiolabelled metabolites of dFdC after a $4 \mathrm{~h}$ incubation with $300 \mathrm{~nm}\left[{ }^{3} \mathrm{H}\right]-\mathrm{dFdC}$, cells were extracted with $200 \mu$ l of ice-cold $0.4 \mathrm{M}$ perchloric acid for 10 min on ice with intermittent scraping with a disposable cell scraper. The resulting suspension was centrifuged at $10000 \mathrm{~g}$ at $4{ }^{\circ} \mathrm{C}$ for $5 \mathrm{~min}$. Supernatant was removed, neutralised with $\mathrm{K}_{2} \mathrm{CO}_{3}$ and used for HPLC analysis. Nucleotide profiles were determined by ion-exchange HPLC, using a Whatman (Clifton, NJ, USA) Partisphere SAX $4.6 \times 125 \mathrm{~mm}$ column $(5 \mu \mathrm{m}$ particles) and a Whatman $10 \times 2.5 \mathrm{~mm}$ AX guard column. The pellet obtained after perchloric acid precipitation was taken up in $300 \mu \mathrm{l}$ of $0.2 \mathrm{M} \mathrm{NaOH}$ and precipitated again by adding an equal volume of $1.2 \mathrm{M}$ perchloric acid. The protein- and DNA-containing fraction was obtained by centrifugation and the pellet dissolved in a final volume of $200 \mu \mathrm{l} \mathrm{NaOH}$. The protein content was determined using bicinchoninic acid solution containing $0.1 \% \mathrm{CuSO}_{4}$ using bovine
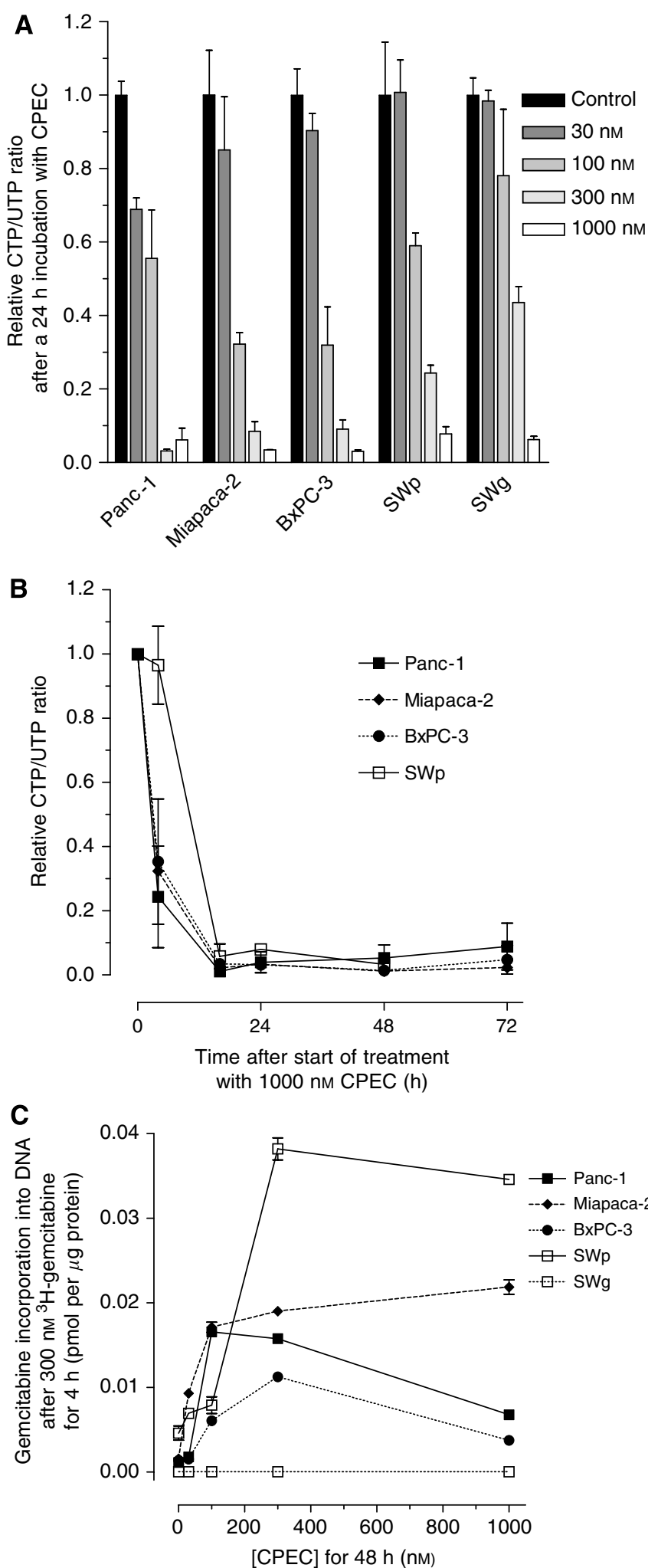

Figure I The effects of CPEC with respect to CTP depletion and to the anabolism of $\mathrm{dFdC}$ in human pancreatic carcinoma (Panc-I, Miapaca-2 and BxPC-3) and NSCLC cells (SWp and its dFdC-resistant variant SWg). Cellular CTP/UTP ratios relative to untreated controls are shown as means with standard errors of at least three separate experiments for the dose dependency at $24 \mathrm{~h}$ after CPEC $(\mathbf{A})$ and for the kinetics after exposure to 1000 nM CPEC (B). Incorporation of dFdC into DNA as a function of CPEC dose for $48 \mathrm{~h}$ preincubation are shown as means with standard errors of at least three separate experiments $(\mathbf{C})$. 
serum albumine as a standard. Radioactivity was detected on-line with a Radiometric 525TR Flow Scintillation Analyser with a $500 \mu \mathrm{l}$ TR-LSC cell (Packard, Meriden, CT, USA) using Ultima Flo AP (Packard, Dowers Grove, IL, USA) at an effluent-to-scintillation fluid ratio of $1: 1$. Radioactivity of the protein pellet was measured on a $\beta$ counter (Bierau et al, 2003).

\section{Clonogenic and proliferation assay}

Cells were harvested at different time points and different treatments, kept on ice, counted, diluted and sparsely plated for standard clonogenic assay (Franken et al (2006); plating efficiencies for Panc-1, Miapaca-2, SWp and SWg cells were $0.62 \pm 0.07$ (mean \pm s.e.), $0.35 \pm 0.08,0.89 \pm 0.10$ and $0.80 \pm 0.08$ respectively). In parallel experiments, the treated cells were plated for proliferation assay at higher densities (8500 cells per $\left.\mathrm{cm}^{2}\right)$ in 6- or 96-well plates to allow reutilisation of dFdC from dying cells (Rockwell and Grindey, 1992). Six-well plates were fixated after 6-10 days with $6 \%$ glutaraldehyde and stained with crystal violet. Wells were scanned with HP Scanjet 5300C using HP Precision Scan-software and HP Intelligent Scanning Technology (version 3.4). Proliferation in 96-well plates was determined by the cell proliferation kit II according to the recommendations of the manufacturer (Roche Diagnostics GmbH, Mannheim, Germany).

\section{Apoptosis by DNA fragmentation assay}

A flow cytometric method was used for measuring the percentage of apoptotic nuclei after propidium iodide staining in hypotonic buffer, and thereby assessing apoptosis of specific cell populations in heterogeneous tissues (Nicoletti et al, 1991). Both detached and attached cells were harvested, pelleted and counted. From each sample, $2 \times 10^{5}$ cells were resuspended in $100 \mu$ l of Nicoletti buffer $\left(0.1 \%\right.$ sodium citrate, $0.1 \%$ Triton $\mathrm{X}-100,50 \mu \mathrm{g} \mathrm{ml}^{-1}$ propidium iodide, dissolved in demi water) and stored for $24 \mathrm{~h}$ at $4{ }^{\circ} \mathrm{C}$. Flow cytometry was performed with FACScan cytometer (BD, San Jose, CA, USA).

\section{Statistical analysis}

Differences in radiosensitivity were analysed using SPSS (Chicago, IL, USA) statistical software by means of a fit of the data by a weighted, stratified, linear regression, according to the linearquadratic formula (Franken et al, 2006). All other differences
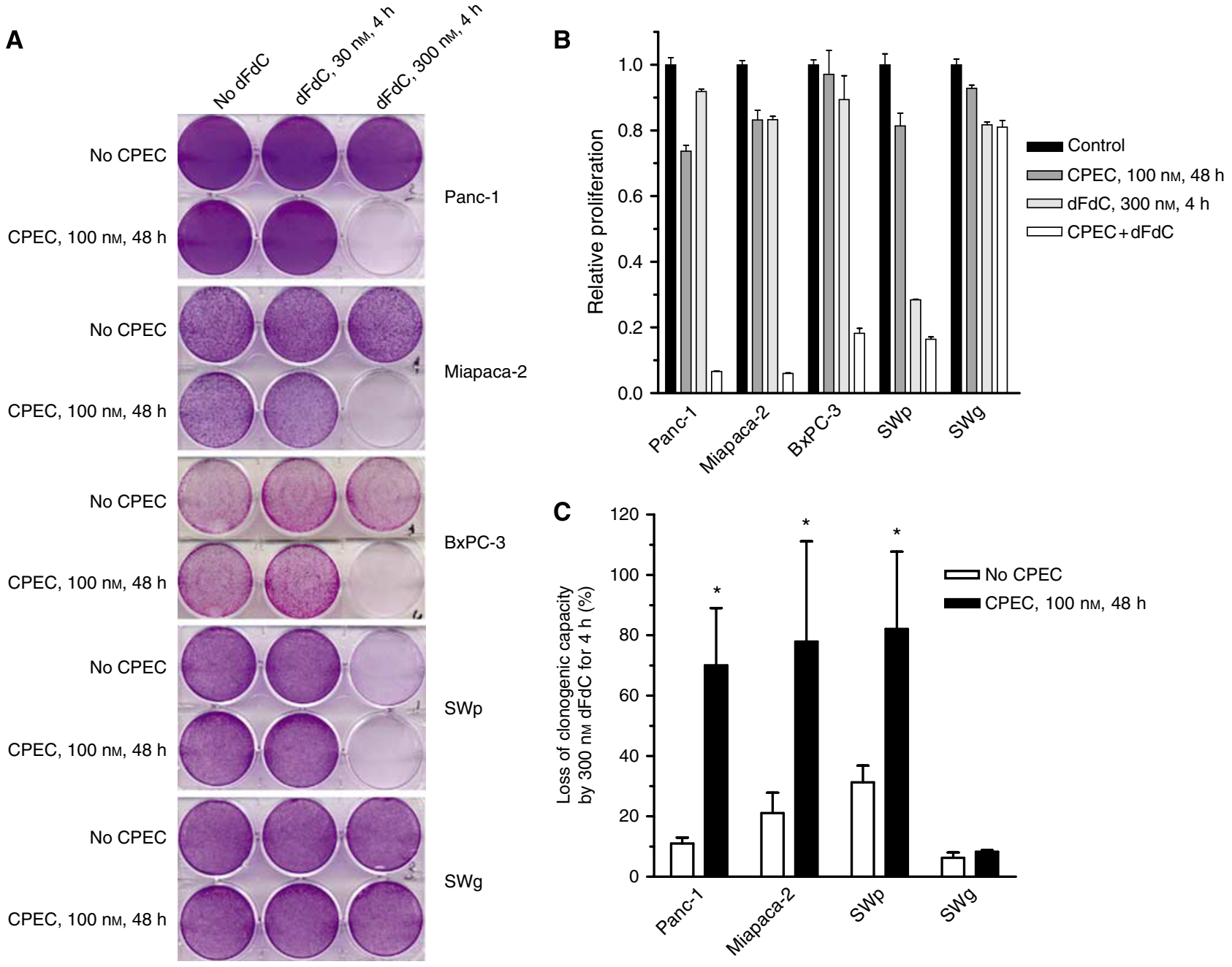

Figure 2 The effects of preincubation with CPEC on the effects of $\mathrm{dFdC}$ with respect to cell proliferation (A and $\mathbf{B})$, loss of clonogenic capacity after correction for the cytotoxicity of CPEC alone ((C) Panc-1: 0.7 I \pm 0.12 ; Miapaca-2: $1.00 \pm 0.06$; SWp: $1.07 \pm 0.08 ;$ SWg: $0.85 \pm 0.26)$ and induction of apoptosis (D) in human pancreatic carcinoma (Panc-I, Miapaca-2 and BxPC-3) and NSCLC cells (SWP and its dFdC-resistant variant SWg). Representative examples $(\mathbf{A}$ and $\mathbf{D})$ or means with standard errors of at least three separate experiments $(\mathbf{B}$ and $\mathbf{C}$, *P<0.05) are shown. 

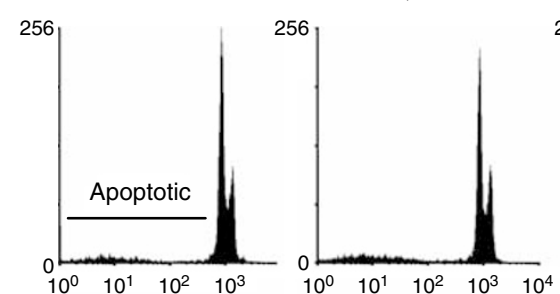

$300 \mathrm{~nm}, 4 \mathrm{~h}$
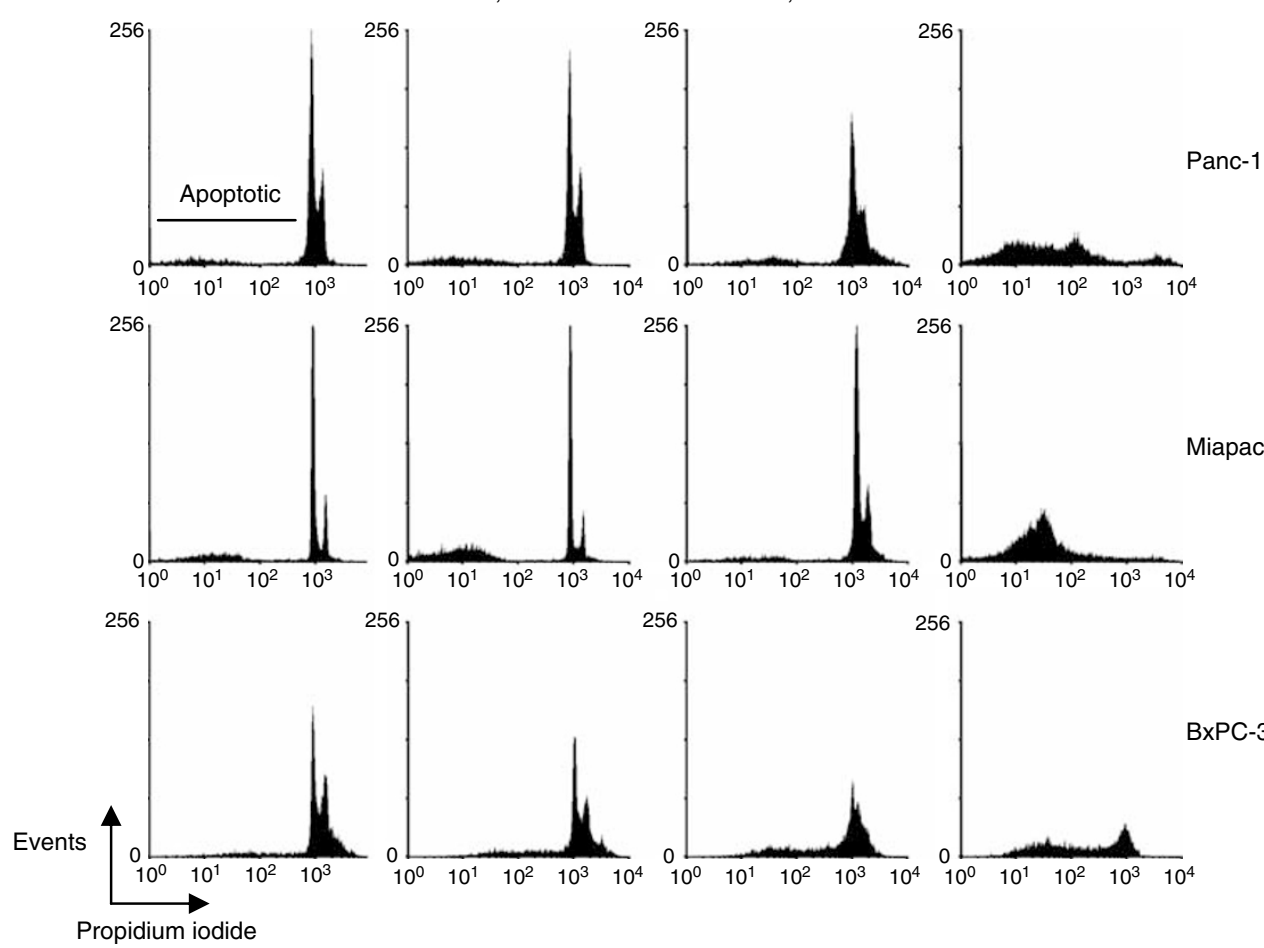

BxPC-3

Figure 2 Continued.

between experimental groups were analysed by the two-tailed Student's $t$-test assuming equal or unequal variances using Microsoft Excel.

\section{RESULTS}

\section{CPEC depletes cellular CTP levels and increases the anabolism of $\mathrm{dFdC}$}

Three widely used human pancreatic carcinoma cell lines, Panc-1, MiaPaca-2 and BxPC-3, in which dFdC-induced radiosensitisation has been described (Lawrence et al, 1996, 1997; Buchsbaum et al, 2002), were selected for this study. First, the ability of CPEC to specifically deplete CTP pools was investigated (Figure 1A and B). In all three cell lines, CPEC specifically reduced CTP/UTP ratios in a dose-dependent manner (Figure 1A) without prominent effects on ATP levels (varying between 0.8 and 1.5 for all data points). Importantly, the decrease in CTP levels was not dependent in the presence of a wild-type $d C K$ activity, as the human NSCLC cell line SWg, which has a disrupted $d C K$ gene (van Bree et al, 2002; Jordheim et al, 2004), showed similar CTP depletion as compared to its parental cell line SWp. The depletion of CTP was already detected at $4 \mathrm{~h}$ of exposure to $1000 \mathrm{~nm}$ CPEC and was almost complete at $16 \mathrm{~h}$ (Figure 1B). The reduction of CTP levels by CPEC was maintained in all cell lines up to $72 \mathrm{~h}$. We next determined the ability of CPEC to enhance the anabolism of dFdC (Figure 1C). The dFdC-resistant cell line SWg served as a control and confirmed the necessity of normal $d C K$ activity for incorporation of dFdC. In all other cell lines, an increase of ${ }^{3} \mathrm{H}-\mathrm{dFdC}$ incorporation into the DNA was observed after preincubation of the cells for $48 \mathrm{~h}$ with CPEC doses as low as $30 \mathrm{~nm}$. For the dFdCsensitive cell lines, a maximal increase in $\mathrm{dFdC}$ incorporation of 10- to 15 -fold was observed at 100-300 nM CPEC.

\section{CPEC increases the efficacy of dFdC}

As an increased anabolism of $\mathrm{dFdC}$ has been shown to enhance the antiproliferative effect of dFdC (Verschuur et al, 2004; Bierau et al, 2006), we determined the treatment efficacy of CPEC and dFdC in our cell panel (Figure 2). Preincubation for $48 \mathrm{~h}$ with $100 \mathrm{nM} \mathrm{CPEC}$ markedly increased the growth inhibitory effect of $\mathrm{dFdC}$, but only at high concentration (Figure $2 \mathrm{~A}$ and $\mathrm{B}$ ). This was also observed for exposures to higher doses of CPEC (up to $1000 \mathrm{nM}$, data not shown). As expected from Figure 1C, CPEC could not increase the sensitivity to $\mathrm{dFdC}$ of the $\mathrm{dFdC}$-resistant SWg cells. In addition to the antiproliferative effects of the combined treatment, we determined the clinically more relevant effects on cell survival by clonogenic assay and on apoptosis. After correction for the toxicity of CPEC alone, we observed that the combined treatment of dFdCsensitive pancreatic cell lines that display clonogenic growth is significantly more effective than $\mathrm{dFdC}$ alone in reducing survival (Figure 2C). We noted that different incubation periods $(24-72 \mathrm{~h}$ ) with CPEC did not induce significant differences in its cytotoxicity nor in dFdC cytotoxicity in Panc-1 and SWp cells. Using DNA fragmentation after treatment as an indicator of apoptosis, we observed that CPEC markedly increased dFdC-induced apoptosis in the three human pancreatic tumour cell lines (Figure 2D). This increase in apoptosis likely contributes to the improved efficacy of dFdC.

\section{CPEC increases $\mathrm{dFdC}$-induced radiosensitisation}

As dFdC is a well-known radiosensitiser of human cancer cells including pancreatic carcinoma cells (Rockwell and Grindey, 1992; Shewach et al, 1994; Lawrence et al, 1996, 1997; Buchsbaum et al, 2002), we investigated the effects of CPEC on dFdC-induced radiosensitisation in our cell panel (Figure 3). In most clinical trials investigating concurrent application of $\mathrm{dFdC}$ and 
A
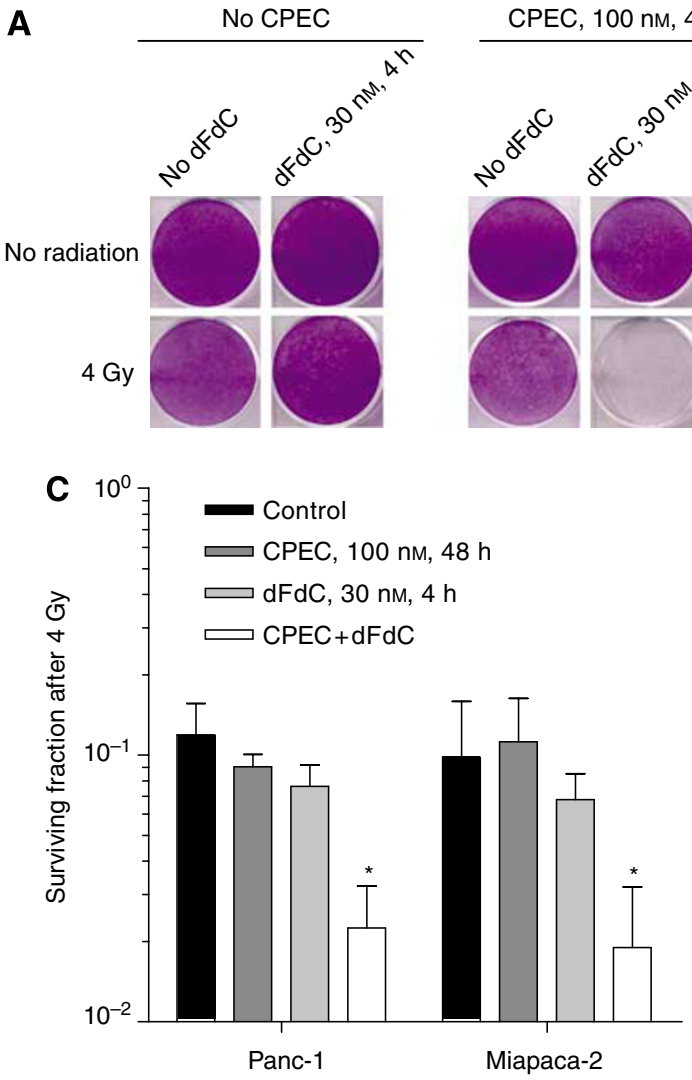

B

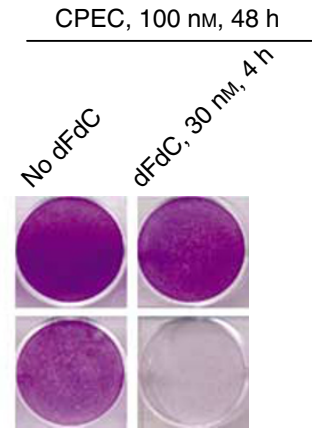

$\mathrm{dFdC}, 30 \mathrm{~nm}, 4 \mathrm{~h}$

$\mathrm{dFdC}, 30 \mathrm{~nm}, 4 \mathrm{~h}$ +4 Gy
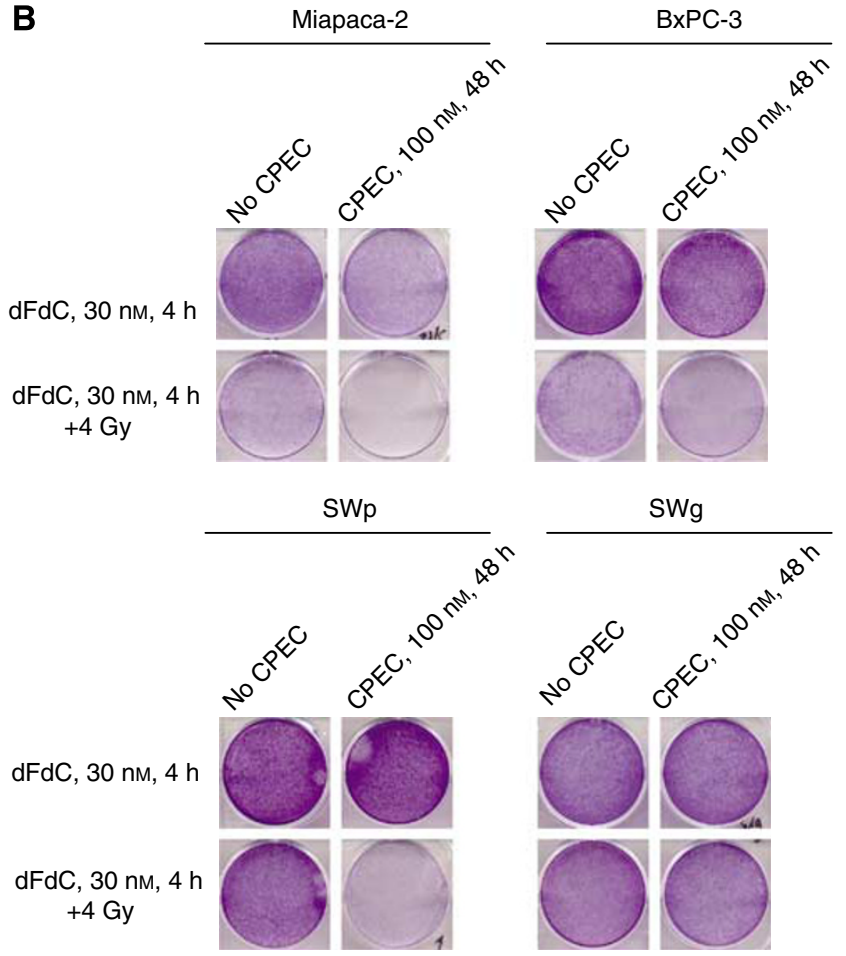

D Control 4 Gy

$\mathrm{CPEC}+\mathrm{dFdC}$
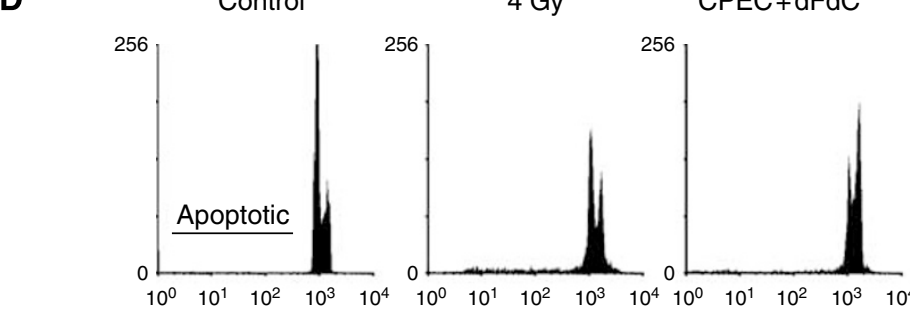

$\mathrm{CPEC}+\mathrm{dFdC}+4 \mathrm{~Gy}$
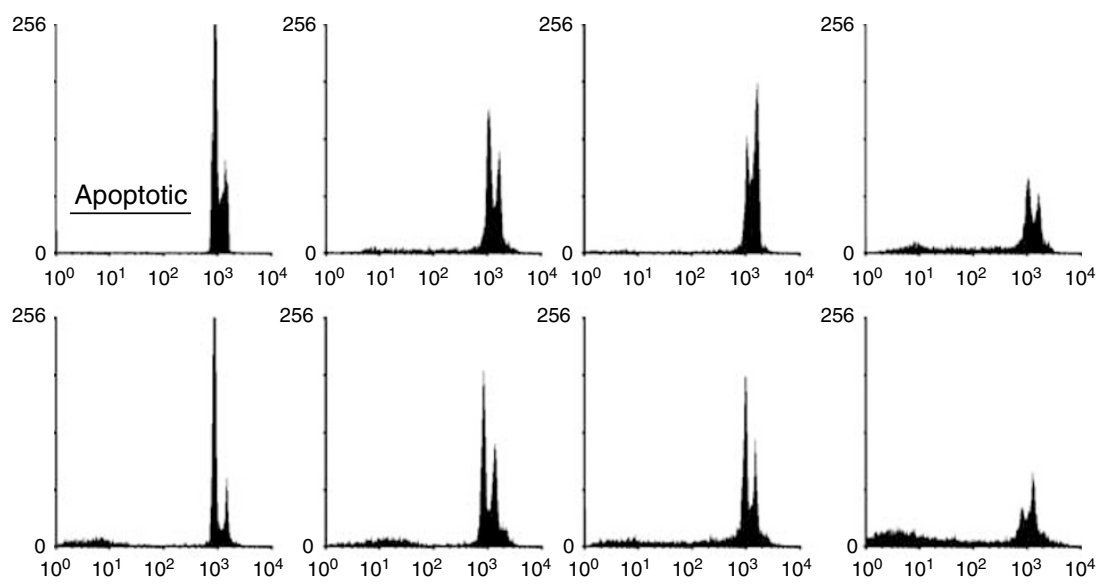

Panc-1
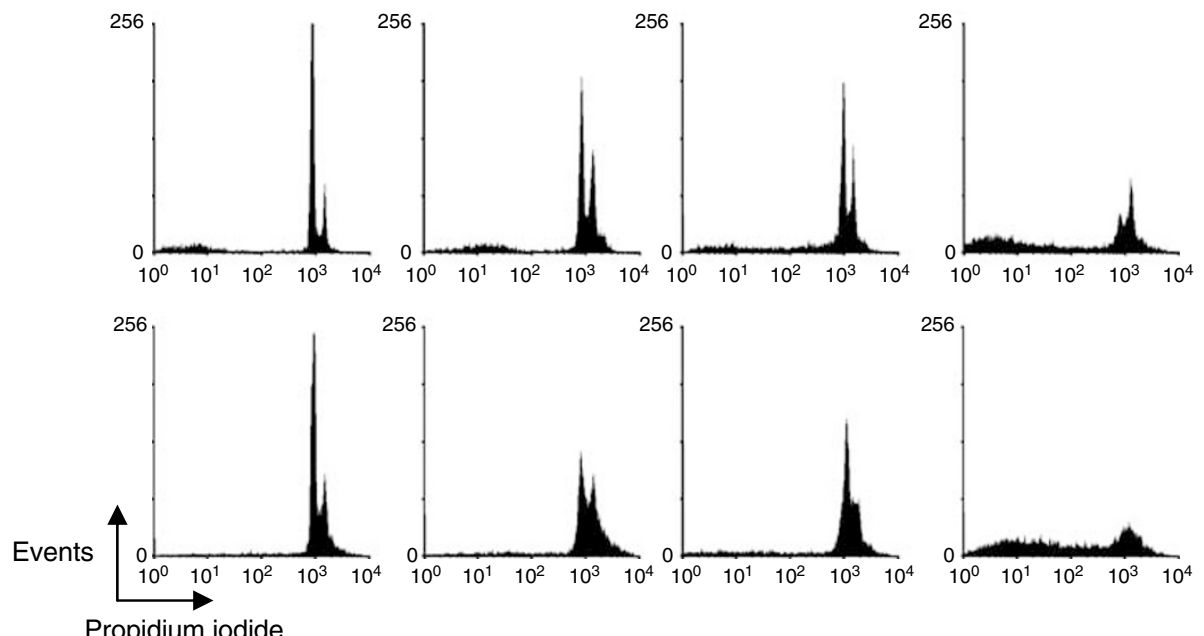

Miapaca-2

BxPC-3

Figure 3 Treatment efficacy of preincubation with CPEC, a nonradiosensitising dose of dFdC and irradiation in human pancreatic carcinoma cells (Panc- I, Miapaca-2, BxPC-3) and NSCLC cells (SWp and its dFdC-resistant variant SWg). Cyclopentenyl cytosine enhanced the efficacy of dFdC combined with radiation with respect to cell proliferation in Panc-I (A) and Miapaca-2, BxPC-3, SWp, but not in SWg cells $(\mathbf{B})$. Clonogenic survival after radiation $(\mathbf{C})$ is shown for Panc-I and Miapaca-2 cells after correction of the toxicity of either treatment without irradiation (Panc- I: CPEC, 0.7I \pm 0.12 ; dFdC, I.0I \pm 0.03 ; CPEC + dFdC, $0.40 \pm$ 0.03; Miapaca-2: CPEC, I.00 \pm 0.06; dFdC, $0.52 \pm 0.20 ; C P E C+d F d C, 0.54 \pm 0.08)$. Induction of apoptosis (D) is shown for Panc- I, Miapaca-2 and BxPC-3. Representative examples (A, B and $\mathbf{D})$ or means with standard errors are shown of at least three separate experiments $(\mathbf{C}, * P<0.05)$. 
A

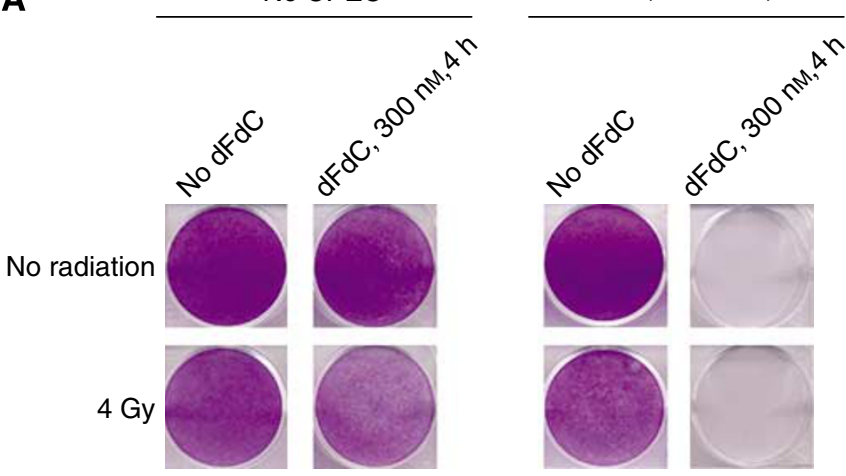

B

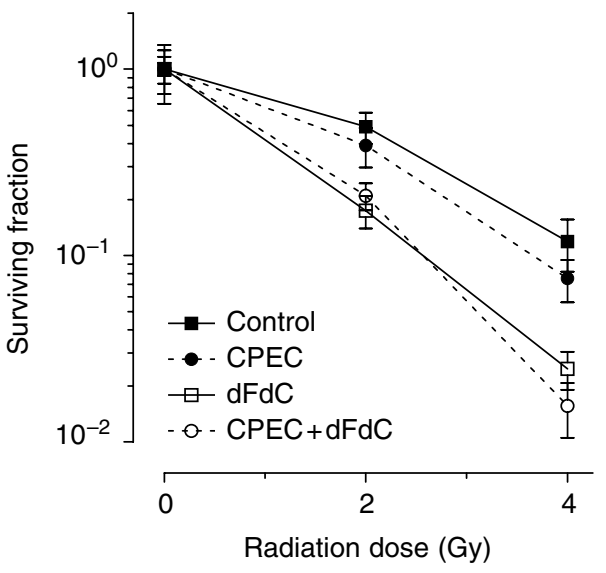

C

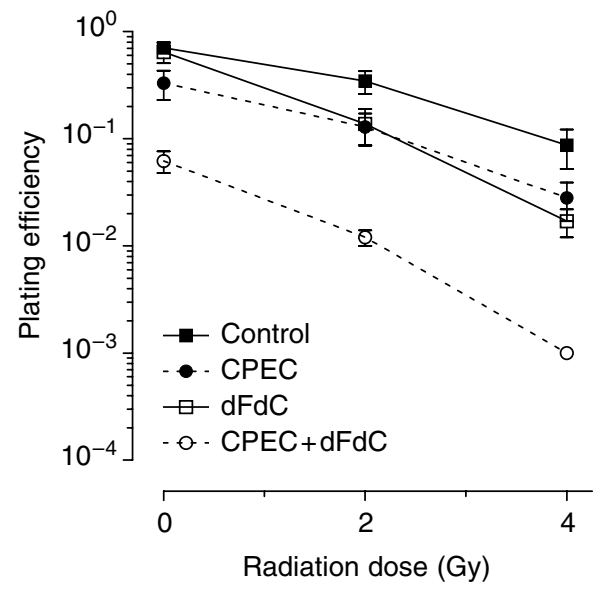

Figure 4 Preincubation with CPEC (1000 nM for 48h) additively enhances dFdC-induced ( $300 \mathrm{nM}$ for $4 \mathrm{~h}$ ) radiosensitisation in human pancreatic carcinoma Panc-I cells. Representative example of a proliferation assay $(\mathbf{A})$ or means with standard errors of at least three separate experiments are shown for clonogenic survival after correction for the toxicity of either treatment alone (B, Panc-I: CPEC, $0.53 \pm 0.16$; dFdC, $0.89 \pm 0.13$; CPEC $+\mathrm{dFdC}, 0.10 \pm 0.02$ ) or for plating efficiency without the correction $(\mathbf{C})$. Significant radiosensitisation was observed for $\mathrm{dFdC}$ alone and for CPEC combined with dFdC (B, $P<0.00 \mathrm{I})$, but not after CPEC alone.

radiotherapy, the $\mathrm{dFdC}$ dose is reduced to circumvent acute gastro-intestinal toxicity (Crane et al, 2001; Wilkowski et al, 2006), which likely reduces treatment efficacy. We therefore studied the interaction with radiation of a lower dose of $\mathrm{dFdC}\left(30 \mathrm{nmoll}^{-1}\right.$ for $4 \mathrm{~h}$ ), which by itself does not induce radiosensitisation (Figure 3 ). In proliferation assays, CPEC, $\mathrm{dFdC}$ and radiation alone hardly affected the growth of Panc-1 cells (Figure 3A). This dFdC dose did not induce radiosensitisation in proliferation or clonogenic assays (Figure 3C). Although CPEC was not able to enhance the efficacy of this lower $\mathrm{dFdC}$ dose, it could clearly inhibit proliferation when combined with $\mathrm{dFdC}$ as well as radiation. This effect was also observed in the other dFdC-sensitive cells, but not in dFdCresistant SWg cells (Figure 3B). Clonogenic survival analysis demonstrated that CPEC could significantly increase the radiosensitivity of Panc-1 and Miapaca-2 cells that were also treated with dFdC (Figure 3C). This increased efficacy of $\mathrm{dFdC}$ and radiation induced by CPEC was again accompanied by an increased apoptosis in all three human pancreatic cell lines (Figure 3D). Subsequently, we investigated whether CPEC influenced the interaction between $\mathrm{dFdC}$ and radiation in a higher dose of $\mathrm{dFdC}\left(300 \mathrm{nmoll}^{-1}\right.$ for $\left.4 \mathrm{~h}\right)$, which may represent the clinical setting in which a full $\mathrm{dFdC}$ dose can be given. In Panc-1 cells, CPEC was again able to completely inhibit proliferation when combined with $\mathrm{dFdC}$ (Figure 4A). A further inhibition of proliferation by the addition of radiation could not be detected. To investigate the possible influence of CPEC with or without $\mathrm{dFdC}$ on radiosensitivity, clonogenic assays were performed (Figure $4 \mathrm{~B}$ ). We observed that $\mathrm{dFdC}$ alone induced significant radiosensitisation in Panc- 1 cells $(P<0.001)$, but that CPEC alone did not. The radiation dose survival curves of CPEC combined with $\mathrm{dFdC}$ and that of $\mathrm{dFdC}$ alone are similar, indicating that in the combined treatment, dFdC-induced radiosensitisation was still present. Similar observations were made for MiaPaca-2 and SWp cells and for preincubation for $48 \mathrm{~h}$ with $100 \mathrm{nmoll}^{-1}$ of CPEC (data not shown). As we demonstrated a significant increase in efficacy of dFdC by preincubation with CPEC (Figure 2C), the plating efficiency, that is, the number of surviving colonies relative to the number of cells plated, after the various treatments is shown (Figure 4C). The combined treatment of CPEC and dFdC combined with radiation is clearly the most effective in reducing cellular survival of Panc-1 cells.

\section{DISCUSSION}

Cyclopentenyl cytosine in its triphosphate form is an antagonist of CTP synthetase, which catalyses the conversion of UTP into CTP. In this paper, we show for the first time that CPEC is able to induce specific depletion of CTP levels in human pancreatic carcinoma and NSCLC cells, which markedly sensitised these cells for treatment with $\mathrm{dFdC}$ alone and in combination with radiation. This was achieved at clinically relevant doses of CPEC that were previously shown to decrease CTP levels in leukaemic samples of 85 adult and paediatric patients (Verschuur et al, 2000) and reduced CTPs activity in bone marrow mononuclear cells of patients treated with CPEC (Politi et al, 1995). Cyclopentenyl cytosine was shown to be active against leukaemia, glioblastoma, neuroblastoma and colon carcinoma (Moyer et al, 1986; Viola et al, 1995; Verschuur et al, 2002; Bierau et al, 2003). In humans, CPEC has been studied in a phase I clinical trial in adults with solid tumours (Politi et al, 1995); 26 patients suffering from predominantly colon carcinoma were treated every 3 weeks with increasing doses of CPEC, ranging from 1 to $5.9 \mathrm{mg} \mathrm{m}^{-2} \mathrm{~h}^{-1}$ for $24 \mathrm{~h}$ (total of 87 cycles). Only mild toxicity was observed in patients with steadystate plasma concentrations below $1.5 \mu \mathrm{M}\left(3.0 \mathrm{mg} \mathrm{m}^{-2} \mathrm{~h}^{-1}\right)$. The most severe toxicity was cardiovascular: six episodes of hypotension occurred in five patients who had been treated with doses ranging from 3.0 to $4.7 \mathrm{mg} \mathrm{m}^{-2} \mathrm{~h}^{-1}$. Two patients treated with $4.7 \mathrm{mg} \mathrm{m}^{-2} \mathrm{~h}^{-1}$ experienced fatal hypotension, which has never been fully explained. The conclusion from these results was, therefore, not to proceed clinically with CPEC as a single agent for solid tumours, but to investigate the exploitation of its targeting effect on CTPs.

Targeting of the de novo pathway for the synthesis of nucleotides by RNAi against a subunit of ribonucleotide reductase 
has proven to be an effective strategy to enhance the effectiveness of $\mathrm{dFdC}$ in a xenograft pancreatic model (Duxbury et al, 2004). Recently, CPEC has been shown to enhance dFdC effectiveness in human leukaemia (Verschuur et al, 2004) and in human neuroblastoma cells (Bierau et al, 2006). Similar to our findings in human pancreatic carcinoma and NSCLC cells, CPEC enhances the incorporation of $\mathrm{dFdC}$ and other nucleotide analogues such as cytarabine into the DNA (Verschuur et al, 2002, 2004; Bierau et al, $2003,2006)$. A decrease in the feedback inhibition of dCTP on $d C K$ was suggested to be the underlying mechanism (Verschuur et al, 2004; Bierau et al, 2006). But even a 2-h exposure to CPEC, which is probably too short to influence $d C K$ activity, already increased the anabolism of cytarabine (Verschuur et al, 2002). The specific depletion of CTP by CPEC may therefore be more important in the enhanced anabolism of $\mathrm{dFdC}$ and cytarabine. Another drug, which depletes cellular nucleotide pools, is the multitargeted antifolate pemetrexed (Giovannetti et al, 2004). Although less specific as compared to CPEC, pemetrexed has also been shown to synergistically interact with $\mathrm{dFdC}$ in human pancreatic cancer cells (Giovannetti et al, 2004). To our knowledge, these strategies have not been applied in combination with radiation, which has been shown to alleviate pain in patients with locally advanced pancreatic cancer (Ceha et al, 2000). Although there is insufficient evidence to recommend chemoradiation in patients with locally advanced inoperable pancreatic cancer as a superior alternative to $\mathrm{dFdC}$ alone (Yip et al, 2006), an increase in treatment efficacy is clearly required for this patient group (Wilkowski et al, 2006; Yip et al, 2006; Murphy et al, 2007; Yamazaki et al, 2007).

Both in vitro and in vivo, $\mathrm{dFdC}$ is a potent enhancer of the cytotoxic effects of ionising radiation (Rockwell and Grindey, 1992; Shewach et al, 1994; Lawrence et al, 1996, 1997; Buchsbaum et al, 2002). Our results show that the increased incorporation of $d F d C$ by CPEC clearly enhanced the efficacy of dFdC, which was shown for proliferation as well as for clonogenic survival. An elevated induction of apoptosis is likely to be one of the underlying mechanisms. For the interaction with radiation, an additive enhancement was observed if a radiosensitising dose of $\mathrm{dFdC}$ was used and a more than additive interaction if a nonradiosensitising dose of $\mathrm{dFdC}$ was used. This is in agreement with earlier findings that radiation enhancement by $\mathrm{dFdC}$ increases with increasing $\mathrm{dFdC}$ dose, but with an optimum, likely to be due to its inhibitory effect on $d C K$ at higher concentrations (Shewach et al, 1994). Recently, the simultaneous alteration of the de novo and salvage pathway to the deoxynucleoside triphosphate pool by (E)$2^{\prime}$-deoxy-(fluoromethylene)cytidine and zidovudine has also been shown to increase the radiosensitivity of human colon cancer cells in vitro (Coucke et al, 2007). Our survival data were obtained using a standard clonogenic assay in which sparsely plated cells are used (Franken et al, 2006). When similar cell numbers were plated in higher density, the interaction of CPEC, $\mathrm{dFdC}$ and radiation appears to be more impressive. This phenomenon, called reutilisation, has been noted earlier for $\mathrm{dFdC}$ and has been suggested to be the cause for the efficacy of dFdC in solid tumours (Rockwell and Grindey, 1992; Haveman et al, 1995). These observations were verified in all three human pancreatic carcinoma cells as well as in human NSCLC cells. Moreover, the importance of an intact $d C K$ gene in this interaction was demonstrated by the dFdC-resistant variant of the human NSCLC SWp (van Bree et al, 2002; Jordheim et al, 2004). The observed differences in $\mathrm{dFdC}$ incorporation between the cell lines used in this study suggest that they differ in $d C K$ activity. Cyclopentenyl cytosine clearly enhanced the $\mathrm{dFdC}$ incorporation in cells with an intact $d C K$ gene, which may be related to an enhanced $d C K$ activity (Bierau et al, 2006). This would be in agreement with the finding that the $d C K$ activity correlates with $\mathrm{dFdC}$-induced radiosensitisation (Gregoire et al, 2002).

In conclusion, we report that CPEC in a low, clinically achievable and nontoxic dose increases dFdC effectiveness as well as its radiosensitising effect in human pancreatic carcinoma cells. Since heterogeneous chemotherapeutic distributions are inherent to solid tumours (Jain, 2001), the combination of CPEC, $\mathrm{dFdC}$ and radiation appears to be a promising strategy for patients with locally advanced pancreatic cancer. The influence of CPEC on therapeutic ratio of $\mathrm{dFdC}$ combined with radiation in pancreatic xenograft models is warranted for future clinical application.

\section{ACKNOWLEDGEMENTS}

We are very grateful to Judith de Vos and Richard Pian for technical assistance and to Klaas Franken and Geertjan van Tienhoven for critically reviewing the manuscript. The Maurits and Anna de Kock foundation is acknowledged for sponsoring laboratory equipment.

\section{REFERENCES}

Bierau J, van Gennip AH, Leen R, Helleman J, Caron HN, van Kuilenburg $\mathrm{AB}$ (2003) Cyclopentenyl cytosine primes SK-N-BE(2)c neuroblastoma cells for cytarabine toxicity. Int J Cancer 103: 387-392

Bierau J, van Gennip AH, Leen R, Meinsma R, Caron HN, van Kuilenburg AB (2006) Cyclopentenyl cytosine-induced activation of deoxycytidine kinase increases gemcitabine anabolism and cytotoxicity in neuroblastoma. Cancer Chemother Pharmacol 57: 105-113

Buchsbaum DJ, Bonner JA, Grizzle WE, Stackhouse MA, Carpenter M, Hicklin DJ, Bohlen P, Raisch KP (2002) Treatment of pancreatic cancer xenografts with Erbitux (IMC-C225) anti-EGFR antibody, gemcitabine, and radiation. Int J Radiat Oncol Biol Phys 54: 1180-1193

Burris III HA, Moore MJ, Andersen J, Green MR, Rothenberg ML, Modiano MR, Cripps MC, Portenoy RK, Storniolo AM, Tarassoff $P$, Nelson R, Dorr FA, Stephens CD, Von Hoff DD (1997) Improvements in survival and clinical benefit with gemcitabine as first-line therapy for patients with advanced pancreas cancer: a randomized trial. J Clin Oncol 15: $2403-2424$

Ceha HM, van Tienhoven G, Gouma DJ, Veenhof CH, Schneider CJ, Rauws EA, Phoa SS, Gonzalez Gonzalez D (2000) Feasibility and efficacy of high dose conformal radiotherapy for patients with locally advanced pancreatic carcinoma. Cancer 89: 2222-2229
Coucke PA, Cottin E, Decosterd LA (2007) Simultaneous alteration of de novo and salvage pathway to the deoxynucleoside triphosphate pool by (E)-2'-Deoxy-(fluoromethylene)cytidine (FMdC) and zidovudine (AZT) results in increased radiosensitivity in vitro. Acta Oncol 46: 612-620

Crane $\mathrm{CH}$, Antolak JA, Rosen II, Forster KM, Evans DB, Janjan NA, Charnsangavej C, Pisters PW, Lenzi R, Papagikos MA, Wolff RA (2001) Phase I study of concomitant gemcitabine and IMRT for patients with unresectable adenocarcinoma of the pancreatic head. Int J Gastrointest Cancer 30: 123-132

Duxbury MS, Ito H, Zinner MJ, Ashley SW, Whang EE (2004) RNA interference targeting the M2 subunit of ribonucleotide reductase enhances pancreatic adenocarcinoma chemosensitivity to gemcitabine. Oncogene 23: 1539-1548

Franken NA, Rodermond HM, Stap J, Haveman J, van Bree C (2006) Clonogenic assay of cells in vitro. Nat Protoc 1: 2315-2319

Giovannetti E, Mey V, Danesi R, Mosca I, Del Tacca M (2004) Synergistic cytotoxicity and pharmacogenetics of gemcitabine and pemetrexed combination in pancreatic cancer cell lines. Clin Cancer Res 10: $2936-2943$

Gregoire V, Rosier JF, De Bast M, Bruniaux M, De Coster B, Octave-Prignot M, Scalliet P (2002) Role of deoxycytidine kinase (dCK) activity in 
gemcitabine's radioenhancement in mice and human cell lines in vitro. Radiother Oncol 63: 329-338

Haveman J, Rietbroek RC, Geerdink A, Van Rijn J, Bakker PJ (1995) Effect of hyperthermia on the cytotoxicity of $2^{\prime}, 2^{\prime}$-difluorodeoxycytidine (gemcitabine) in cultured SW1573 cells. Int J Cancer 62: 627-630

Jain RK (2001) Delivery of molecular and cellular medicine to solid tumours. Adv Drug Deliv Rev 46: 149-168

Jordheim L, Cros E, Galmarini CM, van Bree C, Dumontet C (2004) Deoxycytidine kinase gene alterations in gemcitabine-resistant cell lines. Proc Am Assoc Cancer Res 45: 618a

Kang GJ, Cooney DA, Moyer JD, Kelley JA, Kim HY, Marquez VE, Johns DG (1989) Cyclopentenylcytosine triphosphate. Formation and inhibition of CTP synthetase. J Biol Chem 264: 713-718

Kizaki H, Williams JC, Morris HP, Weber G (1980) Increased cytidine 5 -triphosphate synthetase activity in rat and human tumors. Cancer Res 40: $3921-3927$

Lawrence TS, Chang EY, Hahn TM, Hertel LW, Shewach DS (1996) Radiosensitization of pancreatic cancer cells by $2^{\prime}, 2^{\prime}$-difluoro-2'-deoxycytidine. Int J Radiat Oncol Biol Phys 34: 867-872

Lawrence TS, Chang EY, Hahn TM, Shewach DS (1997) Delayed radiosensitization of human colon carcinoma cells after a brief exposure to $2^{\prime}, 2^{\prime}$-difluoro-2'-deoxycytidine (Gemcitabine). Clin Cancer Res 3: $777-782$

Moyer JD, Malinowski NM, Treanor SP, Marquez VE (1986) Antitumor activity and biochemical effects of cyclopentenyl cytosine in mice. Cancer Res 46: 3325 - 3329

Murphy JD, Adusumilli S, Griffith KA, Ray ME, Zalupski MM, Lawrence TS, Ben-Josef E (2007) Full-dose gemcitabine and concurrent radiotherapy for unresectable pancreatic cancer. Int J Radiat Oncol Biol Phys 68: $801-808$

Nicoletti I, Migliorati G, Pagliacci MC, Grignani F, Riccardi C (1991) A rapid and simple method for measuring thymocyte apoptosis by propidium iodide staining and flow cytometry. J Immunol Methods 139: $271-279$

Politi PM, Xie F, Dahut W, Ford Jr H, Kelley JA, Bastian A, Setser A, Allegra CJ, Chen AP, Hamilton JM, Arbuck SF, Linz P, Brammer H, Grem JL (1995) Phase I clinical trial of continuous infusion cyclopentenyl cytosine. Cancer Chemother Pharmacol 36: 513-523
Rockwell S, Grindey GB (1992) Effect of $2^{\prime}, 2^{\prime}$-difluorodeoxycytidine on the viability and radiosensitivity of EMT6 cells in vitro. Oncol Res 4: $151-155$

Shewach DS, Hahn TM, Chang E, Hertel LW, Lawrence TS (1994) Metabolism of $2^{\prime}, 2^{\prime}$-difluoro- $2^{\prime}$-deoxycytidine and radiation sensitization of human colon carcinoma cells. Cancer Res 54: 3218-3223

van Bree C, Castro Kreder N, Loves WJ, Franken NA, Peters GJ, Haveman J (2002) Sensitivity to ionizing radiation and chemotherapeutic agents in gemcitabine-resistant human tumor cell lines. Int J Radiat Oncol Biol Phys 54: $237-244$

Verschuur AC, Van Gennip AH, Leen R, Meinsma R, Voute PA, van Kuilenburg $\mathrm{AB}$ (2000) In vitro inhibition of cytidine triphosphate synthetase activity by cyclopentenyl cytosine in paediatric acute lymphocytic leukaemia. Br J Haematol 110: 161-169

Verschuur AC, Van Gennip AH, Leen R, Van Kuilenburg AB (2004) Increased cytotoxicity of $2^{\prime}, 2^{\prime}$-difluoro- $2^{\prime}$-deoxycytidine in human leukemic cell-lines after a preincubation with cyclopentenyl cytosine. Nucleosides Nucleotides Nucleic Acids 23: 1517-1521

Verschuur AC, Van Gennip AH, Leen R, Voute PA, Brinkman J, Van Kuilenburg AB (2002) Cyclopentenyl cytosine increases the phosphorylation and incorporation into DNA of 1-beta-D-arabinofuranosyl cytosine in a human T-lymphoblastic cell line. Int J Cancer 98: $616-623$

Viola JJ, Agbaria R, Walbridge S, Oshiro EM, Johns DG, Kelley JA, Oldfield EH, Ram Z (1995) In situ cyclopentenyl cytosine infusion for the treatment of experimental brain tumors. Cancer Res 55: 1306-1313

Wilkowski R, Thoma M, Bruns C, Wagner A, Heinemann V (2006) Chemoradiotherapy with gemcitabine and continuous 5-FU in patients with primary inoperable pancreatic cancer. JOP 7: 349-360

Yamazaki $\mathrm{H}$, Nishiyama K, Koizumi $M$, Tanaka $E$, Ioka T, Uehara $H$, Iishi H, Nakaizumi A, Ohigashi H, Ishikawa O (2007) Concurrent chemoradiotherapy for advanced pancreatic cancer: $1000 \mathrm{mg} / \mathrm{m}^{2}$ gemcitabine can be administered using limited-field radiotherapy. Strahlenther Onkol 183: $301-306$

Yip D, Karapetis C, Strickland A, Steer CB, Goldstein D (2006) Chemotherapy and radiotherapy for inoperable advanced pancreatic cancer. Cochrane Database Syst Rev 3: ART. No. CD002093 DOI:10.1002/ 14651858. CD002093.pub2 